information is put to and to whom it is revealedalways assuming, of course, that no one else's welfare is at stake here. Even if the records, as physical objects, are government property it does not follow that this is true also of the information that they contain. Personal information disclosed in a consultation should perhaps be seen as effectively "on trust" to the doctor for the period of treatment, or for the period in which that doctor continues to have the person as a patient. (The whole issue of ownership of information is one that would merit more attention from moral philosophers.)

Other arguments of a more pragmatic character will no doubt be advanced in favour of maintaining the status quo. One should be reluctant, it may be said, to advocate any new system that would add to the administrative burden under which hard pressed general practitioners and the NHS generally, currently labour. Some sacrifice of patient autonomy may be justified on the basis that it is a relatively small price to pay in return for the very great benefits of the present system, which allows the use of information collected over a long time to be used whenever required in a consultation. But even in therapeutic terms there could be much to be gained by a system that gave patients greater control over their own records; it might well serve to encourage greater openness, enhanced trust, and a greater spirit of cooperation between doctor and patient. We find it difficult to believe that a system more respectful of confidentiality and of the patient's wishes could not be made to work successfully if there was a sufficient will so to do.

1 General Medical Council. Professional conduct and discipline: fitness to practice. London: GMC, 1987:sections 79-88.

\title{
Escape from collective denial: HIV transmission during surgery
}

\author{
A G Bird, S M Gore, A J Leigh-Brown, D C Carter
}

Surgeons are rightly concerned about the risk of acquiring HIV infection when performing operations, ${ }^{1}$ and the risk to patients from an infected surgeon with HIV has been highlighted by two recent events. The Centers for Disease Control reported that an American dentist with AIDS infected as many as five patients during dental care, ${ }^{2}$ and in Britain an infected gynaecologist agreed responsibly that patients he had operated on should be contacted. In the case of the dentist there was unusual similarity in nucleotide sequences of HIV provirus from the dentist and his five patients and two female patients had no other established risk factors for acquiring HIV. Although HIV was prevalent by the late 1970 s in the US, these are the first reported cases of probable operative transmission from a health care worker.

\section{Transmission of bloodborne viruses during surgery}

Members of a surgical team risk percutaneous injuries that could expose either the operator or patient to bloodborne infection. Such injuries occur in $2 \%$ to $15 \%$ of operative procedures, ${ }^{4-5}$ one third of which result in possible reverse exposure (Tokars et al, AIDS conference 1991, Florence).

Transmission of hepatitis B virus from such incidents

HIV Immunology Unit, Royal Infirmary, Edinburgh EH3 9YW

A G Bird, FRCP, senior lecturer

Medical Research Council

Biostatistics Unit,

Cambridge CB2 2BW

S M Gore, PHD, senior

statistician

B Division of Biological Sciences, University of Edinburgh EH9 3JN A J Leigh-Brown, PHD, lecturer

Department of Surgery, Royal Infirmary, Edinburgh EH3 9YW

D C Carter, FRCS, professor of

clinical surgery

Correspondence to: Dr Bird.

BMF 1991;303:351-2 patient. Transmission of the virus can occur at relatively high frequency. Screening of 247 patients operated on by one gynaecologist infected with hepatitis B virus showed that $22(9 \%)$ had markers of hepatitis B infection; the infected women included almost a quarter of those who had undergone hysterectomy (10/42). ${ }^{6}$ Classifying procedures within each surgical specialty as high, medium, or low risk for viral transmission is therefore sensible. ${ }^{?}$

\section{Risk to health care workers from patients}

The transmission of HIV to health care workers after percutaneous injury is being documented prospectively ${ }^{8}$; infection occurs in about $0.4 \%$ of cases but may be influenced by the size of the inoculum..$^{910}$ Hepatitis B virus poses a considerably greater risk than HIV with seroconversion rates of $6 \%$ to $30 \%$ reported after percutaneous incidents involving patients positive for the e antigen. ${ }^{112}$

\section{Assessment of risk of HIV transmission by health workers}

The risk of HIV transmission from an infected health worker during surgery has not been extensively analysed. Only three retrospective studies have been reported, ${ }^{71314}$ yet in Britain alone we estimate that six dentists and 1.6 surgeons have had AIDS diagnosed. ${ }^{1516}$

In the largest American investigation, testing for HIV antibodies was offered to 1652 patients contacted after a surgeon developed AIDS; 616 (37\%) accepted testing and only one positive result was found in a known intravenous drug misuser. ${ }^{13}$ In a British study 339 patients operated on by a surgeon subsequently found to be HIV positive were contacted and $76(22 \%)$ were tested, all of whom had negative results. ${ }^{7}$

Despite the reassurance of these reports, similarities in the modes of transmission of hepatitis B virus and HIV and the evidence of transmission during dental surgery suggest that perioperative infection will occur, although it is uncertain how often. HIV infection has a long latency so that cases of AIDS appear a long time after surgery and will be more difficult to relate to a surgical event than acute hepatitis associated with hepatitis B virus. ${ }^{12}$ There are currently no virological markers for the likelihood of transmission from individual health workers infected with HIV. ${ }^{17}$

\section{Epidemiological requirements}

The need for data to assess the risk of HIV infection to health care workers has never been questioned yet the same systematic approach has not been adopted for patients. The Royal College of Surgeons in Edinburgh have asked that surgeons should have the right to test for HIV antibodies in patients at risk of infection; they have not suggested anonymised testing of surgeons to quantify the extent of occupational risk. Following the initial Centers for Disease Control report of transmission during dental surgery a working group of the New York Academy of Medicine issued a statement decrying the "substantial public anxiety created concerning what is in fact minimal risk" but did not recommend any studies to document the level of transmission resulting from surgical or dental procedures. ${ }^{18}$ In April 1991 the Department of Health orchestrated that public health officials contact over 1000 women operated on by an infected gynaeco- 
logical surgeon and then reassured the women that they did not require HIV tests. ${ }^{19}$

We propose that national epidemiological centres should monitor all patients who receive care from HIV positive health workers involved in surgical procedures. The monitoring should be coordinated by an international panel of experts that could use the information to classify the range of surgical procedures into levels of exposure risk, and produce protocols to specify the extent of systematic review, counselling, and testing of patients required. Any cases of suspected nosocomial transmission should be further investigated by analysing the nucleotide sequence of provirus from index health workers and their patients. ${ }^{20}$ Should suspected cases of transmission be verified, further investigations (including case-control studies to classify risk) will be required.

Other epidemiological studies that could be conducted immediately include investigation of previous dental or general surgery in people with AIDS presenting with undetermined risk factors, and a regularly updated search of AIDS registrations and death certificates for patients operated on by surgeons or dentists known to be infected with HIV. ${ }^{131421}$

Barriers to comprehensive studies could be removed by advance planning. Lifting life or medical insurance exclusions for those participating in epidemiological surveys, availability of specialised counselling, rapid HIV test results, and anonymised testing for those not wishing named investigation would all enhance compliance. The British expert advisory group on AIDS recommended that people with AIDS or AIDS related complex should not participate in surgical invasive procedures. ${ }^{12}$ Cooperation from health care workers could be improved by providing approbation for HIV disclosure, clearly identified future career choices, and financial security in the event of HIV infection..$^{22}$

\section{Difficult balance}

It has proved difficult to strike a balance between general reassurance of patients and the need to establish comprehensive epidemiological surveillance. In the only published British study of patients operated on by an infected surgeon only $22 \%$ of all patients (and 32\% of those with potential high level exposure) had been tested for HIV - too few to allow reliable assessment.' The 1000 women operated on by a gynaecologist who was subsequently found to be HIV positive were all offered counselling by telephone helpline, but HIV tests were offered only to those who pursued their request further. Press statements by public health officials described the risk to patients as "infinitesimal" and stated that the patients "did not need HIV tests." 1923 Patients requesting HIV tests would in many cases have had to present to genitourinary medicine clinics for further pretest counselling and testing. Reacting to press headlines, the Association of British Insurers took the initiative of recommending a waiver for patients being tested for HIV on this occasion. But because the Department of Health failed to approach the association this information was not initially available to the local health authorities handling cases. It was also not mentioned in the briefing document issued to counsellors. Moreover, counselling advice and official public statements failed to identify published information about transmission from the Florida dental surgeon and indicated only that no cases of HIV transmission by doctors, nurses, or midwives had occurred worldwide. A BBC television programme in June 1991 about the Florida case has made the public better informed, and patients' common sense has meant that although only $22 \%$ operated on by an infected surgeon had requested HIV tests in 1990, in two smaller districts $60 \%$ of women operated on by the infected gynaecologist had requested tests by 1 May 1991.

\section{Escape from collective denial}

Epidemiological assessment of the risk of HIV transmission by health care workers to their patients must not be hindered by the collective denial which has characterised so much of the study of HIV so far. ${ }^{24}$ The medical profession must not shelter behind public statements of "infinitesimal" risk when the surveys required to justify such an assessment have not been performed, ${ }^{22}$ and we cannot exclude differences in infectivity among infected workers or that disease stage might affect transmission. The success of any surveillance exercise should be judged by the level of HIV testing achieved, particularly among patients who have undergone operations that carry a high risk of operator injury and blood exchange (such as hysterectomy and caesarean section).

1 de Cleroq A, Oeyen L. HIV and surgeons. BMF 1991;302:51

2 Centers for Disease Control. Transmission of HIV infection during an invasive dental procedure. $M M W R$ 1991;40:21-7,377-81.

3 Durham H. Gynaecologist in AIDS scare treated 1000. Sunday Times 199 April 7.

4 Gerberding JL, Littell C, Tarkington A, et al. Risk of exposure of surgical personnel to patients' blood during surgery at San Francisco General Hospital. N Engl f Med 1990;319:1788-93.

5 Hussain SA, Latif AB, Choudhary AA. Risk to surgeons: a survey of accidental injuries during operations. Brf Surg 1988;75:314-6.

6 Welch J, Webster M, Tilzey AJ, et al. Hepatitis B infections after gynaecological surgery. Lancet 1989;: $: 205-6$.

7 Porter JD, Cruickshank JG, Gentle PH, et al. Management of patients treated by surgeon with HIV infection. Lancet 1990;335:113-4.

8 Marcus R, Co-operative Needlestick Surveillance Group. Surveillance of Marcus R, Co-operative Needlestick Surveillance Group. Surveillance of
healthcare workers exposed to blood from patients infected with the human healthcare workers exposed to blood from patients infected
immunodeficiency virus. N Engl F Med 1988;319:1118-22.

9 Berglund $\mathrm{O}$, Beckman S, Grillner L, et al. HIV transmission by blood transfusions in Stockholm 1979-1985: nearly uniform transmission from infected donors. AIDS 1988;2:51-4.

10 Lange JMA, Boucher CAB, Hollak CEM, et al. Failure of zidovudine prophylaxis after accidental exposure to HIV-1. N Engl f Med 1990;322 1375-7.

11 Centers for Disease Control. Guidelines for prevention of human immunodeficiency virus and hepatitis B to healthcare and public-safety workers. $M M W R$ 1989;1(suppl 56):3-37.

12 Department of Health and Social Security. AIDS: HIV infected healthcare workers: report of the recommendations by the Expert Advisory Group on AIDS. London: DHSS, 1988.

13 Mishu B, Schaffner W, Horan JM, et al. A surgeon with AIDS. JAMA 1990;264:467-70.

14 Armstrong F, Miner J, Wolfe W. Investigation of a healthcare worker with symptomatic human immunodeficiency virus infection: an epidemiological
approach. Milit Med 1987;152:414-8.

15 Lot F, Bouvet E, Laporte A. SIDA et personnel soignant. Bulletin Epidemiologique Hebdomadaire 1990;49:207-8.

16 Berkelman R. HIV and health care workers. Atlanta: Centers for Diseasc Control, 1990. (Factsheet)

17 Simmonds P. Variation in HIV virus load of individual at different stages in infection: possible relationship with risk of transmission. AIDS in infection: possible
$1990 ; 4$ (suppl 1):577-83.

18 New York Academy of Medicine Working Group. Commentary: the risk of contacting HIV infection in the course of health care. FAMA 1991;265 1872-3.

19 Patients of HIV doctor "do not need AIDS tests." Guardian 1991 April

20 Balfe P, Simmonds P, Ludlam CA, et al. Concurrent evolution of huma immunodeficiency virus type $\mathbb{l}$ in patients infected from the same source; rate of sequence change and low frequency of inactivating mutations. $f$ Virol 1990;64:6221-33.

21 Sacks JJ. AIDS in a surgeon. $N$ Engl f Med 1985;313:1017-8.

22 Manning S. HIV testing of health workers. Journal of the Medical Defence Union 1991;2:43.

23 "No need for tests," patients of AIDS scare surgeon told. Daily Telegraph 199] April 9.

24 Gerbert B, Bleecker J, Miyasaki C, Maguire BT. Possible health care professional-to-patient HIV transmission. Dentists' reactions to a Centres for Disease Control report. FAMA 1991;265:1845-8.

(Accepted 17 fuly 1991) 